\title{
Histopathologic evaluation of postmortem autolytic changes in bluegill (Lepomis macrohirus) and crappie (Pomoxis anularis) at varied time intervals and storage temperatures
}

Jami George, Arnaud J Van Wettere, Blayk B Michaels, Debbi Crain, Gregory A Lewbart

Information is lacking on preserving fish carcasses to minimize postmortem autolysis artifacts when a necropsy cannot be performed immediately. The purpose of this study was to qualitatively identify and score histologic postmortem changes in two species of freshwater fish (bluegill - Lepomis macrochirus; crappie - Pomoxis annularis), at varied time intervals and storage temperatures, to assess the histologic quality of collected samples. A pooled sample of 36 haphazardly selected mix sex individuals of healthy bluegill and crappie were euthanized, stored either at room temperature, refrigerated at $4^{\circ} \mathrm{C}$, or frozen at $-20^{\circ} \mathrm{C}$, and then necropsied at $0,4,24$, and 48 hour intervals. Histologic specimens were evaluated by light microscopy. Data showed that immediate harvesting of fresh samples provides the best quality and refrigeration would be the preferred method of storage if sample collection had to be delayed for up to 24 hours. When sample collection must be delayed more than $24 \mathrm{~h}$, the preferred method of storage to minimize autolysis artifacts is freezing if evaluation of the gastrointestinal tract is most important, or refrigeration if gill histology is most important. The gill arch, intestinal tract, followed by the liver and kidney were the most sensitive organs to autolysis. 
1 RH: HISTOLOGICAL QUALITY OF POSTMORTEM FISH ORGANS

2 HISTOPATHOLOGIC EVALUATION OF POSTMORTEM AUTOLYTIC CHANGES IN BLUEGILL

3 (LEPOMIS MACROCHIRUS) AND CRAPPIE (POMOXIS ANNULARIS) AT VARIED TIME

4 INTERVALS AND STORAGE TEMPERATURES

5 Alternative: 1) EFFECT OF STORAGE TEMPERATURE ON HISTOLOGIC SAMPLE

6 PRESERVATION IN BLUEGILL (LEPOMIS MACROCHIRUS) AND CRAPPIE (POMOXIS

7 ANNULARIS)

Jami George, D.V.M., Arnaud J. Van Wettere, D.V.M., M.S., Ph.D., Dipl. A.C.V.P., Blayk Michaels, Debbi Crain, and Gregory A. Lewbart, V.M.D., M.S., Dipl. A.C.Z.M.

From the North Carolina State University College of Veterinary Medicine, Raleigh, NC 27607, USA

(George, Lewbart), the Utah Veterinary Diagnostic Laboratory, School of Veterinary Medicine,

Department of Animal, Dairy \& Veterinary Sciences, Utah State University, Logan, UT 84341, USA

(Van Wettere), Bass Pro Shops, Springfield, MO 65898 (Michaels, Crain)

Editorial correspondence: Gregory A. Lewbart, NCSU-CVM, 1060 William Moore Drive, Raleigh, NC, 27607; (919)-513-6439; greg_lewbart@ncsu.edu. 
8 Abstract: Information is lacking on preserving fish carcasses to minimize postmortem autolysis artifacts

9 when a necropsy cannot be performed immediately. The purpose of this study was to qualitatively

10 identify and score histologic postmortem changes in two species of freshwater fish (bluegill - Lepomis

11 macrochirus; crappie - Pomoxis annularis), at varied time intervals and storage temperatures, to assess

12 the histologic quality of collected samples. A pooled sample of 36 haphazardly selected mix sex

13 individuals of healthy bluegill and crappie were euthanized, stored either at room temperature,

14 refrigerated at $4{ }^{\circ} \mathrm{C}$, or frozen at $-20^{\circ} \mathrm{C}$, and then necropsied at $0,4,24$, and 48 hour intervals. Histologic

15 specimens were evaluated by light microscopy. Data showed that immediate harvesting of fresh samples

16 provides the best quality and refrigeration would be the preferred method of storage if sample collection

17 had to be delayed for up to 24 hours. When sample collection must be delayed more than $24 \mathrm{~h}$, the

18 preferred method of storage to minimize autolysis artifacts is freezing if evaluation of the gastrointestinal

19 tract is most important, or refrigeration if gill histology is most important. The gill arch, intestinal tract,

20 followed by the liver and kidney were the most sensitive organs to autolysis. 


\section{INTRODUCTION}

22 When death occurs, cellular metabolic activity declines at varying rates, while enzymes proceed

23

24

unchecked. Autolysis results in cellular breakdown with consequences of structural changes that often distort the line between natural and pathological processes (Carson and Hladik 2009; Cooper 2012; Dettmeyer 2011; Elmore 2007; Roe, Gartrell and Hunter, 2012; Sterne, Titley and Christie, 2000; Tavichakorntrakool et al., 2008; Zdravković et al., 2006). Postmortem samples are frequently utilized in clinical studies, forensic investigations, and biomedical research (Tavichakorntrakool et al. 2008). Of the numerous available diagnostic techniques employed, histology is commonplace and offers detection of subtle morphological tissue changes early in disease processes not easily recognized grossly (Heil 2009).

Common knowledge dictates that the shorter the time between death and tissue fixation for histopathologic evaluation, the better tissue preservation will be, leading to more accurate results (Tavichakorntrakool et al. 2008). For various reasons postmortem sample collection is often delayed. Presently there is a lack of information regarding how to best preserve fish carcasses to minimize autolysis until trained personnel can process them for histopathology.

Past investigations have looked at histological findings following prolonged postmortem interval (PMI) in mammals (Dettmeyer 2011; Erlandsson and Munro 2007). The detection of usable microscopic findings in relation to the PMI "is by nature temporary and dependent" due to a multitude of factors (Dettmeyer 2011; Erlandsson and Munro 2007). When considering fish, the factors include, but are not limited to: ectothermy, body size, fat content, management in captivity, handling, habitat, life stage, health status, amount of ingesta, bacterial flora, medications, time, and type of storage (Chow \& Zhang 2011; Cooper 2012; Dettmeyer 2011; Heil 2009; Mukundan, Antony and Nair 1986; Roe et al., 2012; Sterne et al., 2000; Tavichakorntrakool et al., 2008; Tomita et al., 2004; Zdravković et al., 2006). Organs from dead fish are known to autolyze more quickly than mammalian organs and will often mask ante-mortem changes (Ferguson 2006; Heil 2009; Mukundan et al., 1986; Roberts 2012). One possible explanation is that fish cells rapidly utilize glucose and glycogen from the stress of handling and/or shipping which 
46 results in increased lactic acid, a decreased $\mathrm{pH}$, and exacerbation of autolysis at the time of death (Gatica

47 et al., 2008; Mukandan et al., 1986). Improper temperature storage $\left(-1\right.$ to $\left.-4^{\circ} \mathrm{C}\right)$ worsens autolysis due to

48 an enhanced rate of glycolysis (Mukandan et al., 1986; Thomas et al.,1999).

49 Accurate interpretation of gross and microscopic lesions at postmortem relies heavily on good sample preservation and is impeded by autolysis that follows a prolonged PMI (Roe et al., 2012). In the case of wild, farm-raised, or ornamental fishes, there is frequently a long distance between the site of death and a diagnostic facility. Therefore, postmortem examinations are often performed on frozen-thawed, desiccated, and severely autolyzed fishes (Roe et al., 2012). The effects of freezing organs have been well studied and consists of cell membrane lysis, loss of stain uptake, eosinophilic extracellular fluid accumulation, cell shrinkage, fractures, disruption of blood vessel walls, and development of pseudolesions (Baraibar and Schoning 1985; Chow and Zhang, 2011; Roe et al., 2012; Sterne et al., 2000). These artifacts are compounded by autolysis and make interpretation extremely challenging. It is therefore crucial to determine how best to preserve fish carcasses to minimize tissue autolysis and artifacts in order to improve our ability to define changes and diagnose diseases and ultimately better the

60 health and welfare of fish stocks (wild and farmed). The purpose of this study was to qualitatively

61 identify and score histologic postmortem changes in two related species of freshwater fish, bluegill $(L$.

62 macrochirus) and crappie (P. annularis), at varied time intervals and storage temperatures, to assess the histological quality of collected samples.

MATERIALS AND METHODS

A total of 36 bluegill (L. macrochirus) and crappie (P. annularis) scheduled for depopulation at a large commercial retail facility were utilized. These closely related species are members of the Centrarchidae. 
69 They averaged 340 grams and both sexes were haphazardly included. None of the fish were noted to

70 display clinical or gross signs of disease.

71 Experimental design

72 All 36 fish were euthanized by means of tricaine methanesulfonate (MS-222) overdose at 215 ppm, 73 separated into three groups of 10 (mixed species), and then individually double bagged in plastic. The 74 fish remained in bags until processing. Afterward, nine were kept at room temperature $\left(20^{\circ} \mathrm{C}\right)$, nine were refrigerated $\left({ }^{\circ} 4 \mathrm{C}\right)$, and nine were frozen $\left({ }^{\circ}-20 \mathrm{C}\right)$. Necropsies were performed on the remaining three fish from each cohort, deemed the control groups, in which organs were immediately harvested (also known as procedural starting time or the 0 hour mark). Four hours later, organs were harvested from three fish at room temperature and three refrigerated fish, while three fish were removed from the freezer, set to thaw in cool water for 1 hour, and then harvested. This routine was repeated at 24, and $48 \mathrm{~h}$ intervals in which all fish were sampled. Room temperature and internal body temperatures were recorded at the time of collection (Table 1). Samples from all fish were harvested in the following order: gills, upper and lower intestines, spleen, liver, stomach, gonad, posterior kidney, anterior kidney, heart, skin with underlying muscle, and brain. All samples were placed in sealed containers of $10 \%$ neutral buffered formalin (Sigma-Aldrich, St. Louis, Missouri, USA). Every effort was made to handle fish consistently and promptly in order to minimize the impact of minute-level time differences.

The following fixed samples were trimmed, routinely processed for histopathology, and stained with hematoxylin and eosin: gill arch, skin with underlying skeletal muscles and scales, kidney, liver, spleen, gonads, heart, stomach, pyloric caeca, intestines, and brain. Gill arch and skin with underlying skeletal muscle were decalcified with $10 \%$ formic acid for $24 \mathrm{~h}$ prior to processing. Histology evaluation was performed using a Nikon Eclipse 50i microscope (Nikon Instruments Inc, Melville, NY). Samples were evaluated and scored according to the extent of autolysis in the section examined using a semi- 
93 quantitative scale compared to the control samples: minimal autolysis $(<5 \%)$, mild autolysis $(5-10 \%)$,

94 moderate autolysis (10-50\%), and severe autolysis ( $>50 \%)$.

95 Criteria of autolysis

96 Postmortem changes include both autolysis and putrefaction (bacterial breakdown of organs). The

97 definition of autolysis is the self-digestion or degradation of cells by hydrolytic enzymes normally present

98 within cells postmortem (Carson and Hladid, 2009; Mukundan et al., 1986; Zdravković et al., 2006).

99 Criteria for autolysis comprised the following factors. The overall severity of autolysis was based on the

100 number of factors present and the magnitude of change in the affected cells

101

102

103

104

105

106

107

108

109

110

111 All fish and room temperatures just prior to necropsy are listed in Table 1. Autolysis scores for each 112 sample are shown in Table 2.
1. Pyknosis

2. Karyorrhexis

3. Karyolysis

4. The absence of a nucleus due to complete dissolution or lysis

5. Cellular edema/swelling

6. Failure to take up stain or dissipation of

7. Intracytoplasmic vacuolation

8. Putrefaction

9. Altered architecture of tissue unrelated to a pathological process 
114 Fresh samples (control group) (Figure 1)

115 No significant architectural and cellular histologic changes were observed and stain uptake was optimal

116 for all organs. In the gill, mild artifactual secondary lamellar epithelial lifting was the most common

117 finding. Incidental lesions present included few focal aneurisms of the lamellae, mild multifocal lamellar

118 fusion, and secondary hyperplasia of lamellar epithelial (pavement) cells at interlamellar sulci were also 119 present.

120 Within the skin and muscle, artifactual separation of the cuticle and epidermis was present, with minimal

121 lifting of the basement membrane and stratus spongiosum of the dermis. The brain had mild artifactual

122 lifting of the dura matter and mild separation of the stratum periventriculare from the tegmentum. The

123 gastrointestinal villi were present and intact. Within the intestines, focal areas of minimal artifactual

124 lifting of the lamina propria from the intestinal epithelium were appreciated.

126 Samples at 4 hours (Figure 1)

127 All samples had optimal stain uptake and the histological architecture and cellular preservation were good

128 to moderate. Autolytic changes were minimal and it was not possible to distinguish between the skin,

129 liver, pancreas, spleen, gonads, and heart of fish kept refrigerated, frozen for $4 \mathrm{~h}$ or at room temperature.

130 Minimal secondary lamellar epithelial lifting, loss of cellular details at the lamellae tips and mild

131 vacuolation with increase clear spaces between epithelial and basal cell layers of lamellae were present in

132 the refrigerated fish. Similar histologic changes but more pronounced were present in the fish kept frozen

133 and at room temperature. Rare secondary lamellar aneurysms were also present in all groups.

134 Minimal to mild amount of clear spaces were present between myocytes in all groups. Mild to moderate

135 linear fractures were seen between myocytes in the fish kept frozen. 
136 In the kidney, a mild amount of clear spaces were seen between tubules and hematopoietic cells as

137 well as mild autolysis especially in hematopoietic cells were present in all groups.

138 Mild lifting of the dura mater and mild separation of the stratum periventriculare from the tegmentum

139 was present in all groups. Mild increased clear spaces were seen between the stratum fibrosum

140 marginale and the stratum opticum.

141 Small amount of clear spaces separating epithelial cells and rare karyolysis and pyknosis were present

142 in the intestinal mucosa of all fish groups. Minimal to mild increased clear spaces in the intestinal

143 lamina propria and inner circular smooth muscle were present.

144 Testicular samples were lacking in room temperature samples.

146 Samples at 24 hours (Figure 1)

147 All samples had good stain uptake and the histological architecture and cellular preservation were good to

148 poor. With the exception of the gill, autolytic changes were minimal or mild in the fish kept at $4 \mathrm{C}$ for $24 \mathrm{~h}$.

149 In the gill, moderate breakdown of lamellae with epithelial lifting, moderate vacuolization, loss of cellular

150 details and condensation and fragmentation of the nuclei were present.

151 Autolytic changes were mild to moderate in the frozen samples with the exception of the gill. Severe

152 autolysis and dissolution of the gill arch epithelium could be seen, as well as more than $50 \%$ loss of

153 lamellar histologic architecture.

154 Samples at room temperature had moderate to severe autolytic changes, especially prominent in the gill, 155 gastrointestinal tract, and brain. Moderate to severe dissolution of the gill arch epithelium and lamellar 156 histological architecture could be seen, along with the loss of lamellae structure. 
157 In the skin and musculature, minimal autolytic changes were observed in the fish kept refrigerated for $15824 \mathrm{~h}$.

159 In the fish frozen and kept at room temperature, moderate autolysis and loss of the epithelium and mild to 160 moderate freezing artifacts of the musculature could be found in all samples.

161 In the liver, pancreas, spleen and kidney, autolytic changes were mild in refrigerated fish and moderate in 162 the fish kept at room temperature for $24 \mathrm{~h}$. In the frozen samples, autolysis was mild to moderate with occasional fracture artifact seen. Interestingly, changes in the pancreases were mild to moderate, even in the fish kept at room temperature; vacuolation and cellular separation by clear spaces could be seen.

Autolytic changes in the testes and heart were mild in the refrigerated and frozen fish but more pronounced in the fish kept at room temperature. They consisted of mild to moderate nuclear autolysis. Occasional fractures were seen in the frozen samples. In the heart samples kept at room temperature, postmortem bacilli were observed in the blood and cardiac tissue. Deterioration was commonly seen and putrefaction was found in $2 / 3$ of samples. No ovaries were present in the fish collected at the $24 \mathrm{~h}$ time 170 point.

While autolytic changes were mild in the brain and gastrointestinal tract of the fish kept refrigerated,

172 or mild to moderate in the fish kept frozen, autolytic changes were much more pronounced in the fish

173 kept at room temperature. Intestinal villi architecture was maintained, with mild congealing and 174 vacuolation of the epithelium, in refrigerated and frozen samples. Mild to moderate vacuolation and 175 moderate autolysis were seen in the lamina propria and inner circular smooth muscle. Changes were 176 more pronounced in the samples kept at room temperature and postmortem bacterial bacilli were 177 present. 
179 All samples had a mild to moderate decrease in stain uptake and the histological architecture and cellular 180 preservation were mild to poor.

181 Gill arch and skin were moderately to severely autolyzed in all groups. Gills had an empty skeleton-like 182 appearance, with moderate to severe dissolution of the gill arch epithelium and lamellar histological 183 architecture, loss of lamellae structure, and bony destruction and putrefaction. Most of the epithelium 184 was lost in the skin samples. Muscular autolysis was moderate in the fish kept at room temperature and 185 less pronounced in the refrigerated and frozen samples. Mild to moderate freezing artifacts were present 186 in the frozen fish. Putrefaction of the muscle kept at room temperature was evident. The liver, kidney and 187 pancreas kept refrigerated or frozen showed moderate autolysis maintaining histologic structural integrity 188 but with loss of cellular details. Autolysis was severe in the liver, kidney, and pancreas kept at room 189 temperature. The spleen, gonad, heart, and brain were best preserved in the fish kept refrigerated with 190 only mild to moderate autolysis present. Autolysis was most pronounced, severe, in the fish kept at room 191 temperature.

Autolysis of the gastrointestinal tract was least pronounced in the fish kept frozen with moderate preservation of the epithelium; enterocytes brush border was present multifocally. Autolysis and putrefaction of the gastrointestinal tract of the fish kept refrigerated or at room temperature was severe.

As expected, immediate fixation of the organs provided best preservation for histology, while most prominent autolysis occurred in samples kept for 48 hours at room temperature. These results show that when immediate sampling and fixation is not possible but will be performed within 24 hours, then the ideal storage method would be refrigeration. If necropsy must be delayed more than $24 \mathrm{~h}$, refrigeration is the best preservation method, at least up to $48 \mathrm{~h}$, for gill tissue. Interestingly, if histology of the gastrointestinal tract is sought, freezing is superior to refrigeration. Despite the above findings, we 
202 recommend that whenever possible, fresh tissues are fixed immediately in an appropriate fixative, and

203 that for some organs $10 \%$ neutral buffered formalin is not the best choice.

204 Prior research has verified in humans and mammals that the shorter the period is from the time of death

205 to organ fixation, the more accurate acquired data will be (Mukundan et al., 1986; Roe et al., 2012; Sterne

206 et al., 2000; Tavichakorntrakool et al., 2008). Our results support this fact for freshwater fish as well. It

207 is known that drastic temperature changes can hasten autolysis (Mukundan et al. 1986). Temperatures

208 lower than $-1^{\circ} \mathrm{C}$ can enhance glycolysis and thus autolysis (Mukundan et al. 1986). Studies have also

209 shown that elevated temperature can accelerate autolysis (Carson and Hladik 2009; Sterne et al., 2000).

210 Our study found less pronounced autolysis and fewer artifacts develop with refrigeration, as compared to

211 holding the carcass at room temperature, or freezing. Our results are consistent with previous studies on

212 other taxa (Carson and Hladik, 2009; Mukundan et al., 1986, Roe et al., 2012; Sterne et al., 2000).

213 Our results are similar to other studies showing that refrigeration will produce fewer artifacts than

214 freezing regardless of taxa (Baraibar and Schoning 1985; Mukundan et al., 1986; Roe et al., 2012; Sterne

215 et al., 2000). Freeze-thaw effects have been shown to induce cell membrane lysis, fluid shifts into the

216 extracellular space, and disruption of blood vessel walls resulting in blood cell extravasation (Roe et al.,

217 2012). Ice crystal formation produces the spaces seen on histology.

218 Current thoughts state that the onset of autolysis is rapid and more severe in organs that are rich in

219 hydrolytic enzymes such as the pancreas (Carson and Hladik 2009; Dettmeyer 2011). In a suitable acidic

220 environment (low $\mathrm{pH}$ ), these enzymes would digest organs around their site of origin, causing early-on

221 autolytic changes (Carson and Hladik 2009; Dettmeyer 2011). Other research shows the pancreas, with its

222 high content of hydrolytic enzymes, was relatively resistant to postmortem change up to 24 hours after

223 death (Jones and Trump 1975; Tomita et al., 2004). One study stated that shrinkage of the acinar cells in

224 the pancreas was not appreciated until 10 hours postmortem (Tomita et al., 2004). In our study, autolytic

225 changes in the pancreas remained mild to moderate in most fish samples until 24-48 hours had elapsed, 
226 except for the fish kept at room temperature for $48 \mathrm{~h}$. This supports the belief that the presence of

227 hydrolytic enzymes does not necessarily dictate the onset of autolysis, and cell membrane integrity should

228 be a more important consideration (Ilse et al., 1979).

229 The gill arch and gastrointestinal tracts showed autolytic changes first, followed by kidney, liver and

230 brain, then spleen, gonad, and heart. Skin, and skeletal muscle appeared more resistant to autolysis. It has

231 been established that the rate of autolysis is not the same among different cell types, and is possibly

232 affected by the functional state of the cell (Ilse et al., 1979). Autolysis is also less rapid in organs with

233 elastic fibers/collagen (Carson and Hladik 2009; Dettmeyer 2011). Skeletal muscle has been shown to

234 have the greatest delay in postmortem change in rats as compared to the kidney, liver, and heart (Tomita

235 et al., 2004). Muscle does not provide a strong acidic environment after death for autolysis to occur

236 rapidly in (Takeichi et al., 1984). In another study, human skeletal muscle histology remained unchanged

237 until 24 hours at $4^{\circ} \mathrm{C}$, and 6 hours at $25^{\circ} \mathrm{C}$ (Tavichakorntrakool et al., 2008).

238 The gill arch is a dominant site of gas exchange, osmoregulation, acid-base balance, and excretion of

239 nitrogenous waste (Evans et al., 2005). It holds a central role in a fish's physiological response to

240 environmental and internal changes, as well as the principal site of body fluid $\mathrm{pH}$ regulation (Evans et al.,

241 2005). As expected, the gill epithelium exhibited more autolytic change, as opposed to connective tissue,

242 and bone.

243 When comparing the degree of autolysis of the gill epithelium and filaments in refrigerated samples

244 versus frozen samples, autolysis was more pronounced in frozen tissues. Artifacts created through

245 freeze-thaw procedures induced greater alterations in the histological structure, which was often

246 associated with more autolytic criteria. Thawing of the frozen fish in water may have increased the

247 autolysis change in the gills. The effect on gill histology of thawing in air verses water would be

248 interesting to know. 
249 The results of this study are limited to centrarchid fishes with an average bodyweight of 340 grams.

250 Extrapolating to other piscine species, or centrarchids of different sizes, should be undertaken with care,

251 and an understanding that not all fish samples would behave similarly. Unfortunately, for logistical

252 reasons, exact weights for each fish in this study were not recorded. Furthermore, the two species were

253 treated as a population, and not as separate taxa. This limits the study and we recommend that future

254 work in this area more clearly define these criteria.

\section{CONCLUSIONS}

257

258

259

260

261

262

263

264

265

266

267

268

269

270

271

The dynamics involved with postmortem autolysis are numerous. Veterinary pathologists rely heavily on experience and knowledge to determine the cause of death of a variety of species and circumstances, which can often reduce interpretations to being subjective. Compounding this challenge includes unknown PMIs, poor quality sampling, and suboptimal storage. Having an understanding of the longest PMI for a species, which can provide the most reliable data without hindering analyses, as well as the best postmortem storage method, can offer more accurate interpretations of lesions.

Our observations show that organs collected and fixed immediately after death results in optimal preservation for histology of freshwater fish. If sample collection must be delayed for up to $24 \mathrm{~h}$ refrigeration is recommended. Results also suggest that if histology of the gill is most important, refrigeration is the best preservation method at least up to $48 \mathrm{~h}$. However, if histology of the gastrointestinal tract is sought, freezing is superior to refrigeration if sample collection must be delayed more than $24 \mathrm{~h}$. The first organs showing autolysis were the gill arch and gastrointestinal tract (stomach, pyloric caeca, intestines). The second group of organs affected by autolysis was the kidney, liver and brain. The third tier included the gonad, heart, and spleen. Skin and skeletal muscle were the most resistant organs to autolysis. 
272 This study is limited by the fact that all specimens were closely related and of similar size. It is possible

273 that different species, fish of smaller or larger size, or isolated organs might not behave similarly. Studies

274 using different species, or fish of varying sizes, are warranted and would help validate the results of our 275 work.

276

277 Acknowledgments: We would like to thank Ruth Francis-Floyd, Denise Petty, Derek Bossi, and Kent 278 Passingham for their efforts and input on this project and the NCSU-CVM pathology and histology staff 279 for their assistance in interpretation and processing of samples. 


\section{REFERENCES}

Baraibar M. A. \& Schoning P. (1985) Effects of freezing and frozen storage on histological characteristics of canine tissues. Journal of Forensic Science 30 (2):439-447.

Carson F. L. \& Hladik C. (2009) Histotechnology: A Self-Instructional Text, $3^{\text {rd }}$ ed. American Society for Clinical Pathology Press, Hong Kong, China.

Chow M., \& Zhang Y. (2011) Changes in the mechanical and biochemical properties of aortic tissue due to cold storage. Journal of Surgical Research 171(2): 434 - 442.

Cooper J. E. (2012) The estimation of post-mortem interval (PMI) in reptiles and amphibians: Current knowledge and needs. Journal of Herpetology 22: 91-96.

Dettmeyer R. B. (2011) Forensic Histopathology: Fundamentals and Perspectives. Springer-Verlag Berlin Heidelberg, New York, N.Y.

Elmore S. (2007) Apoptosis: A review of programmed cell death. Toxicologic Pathology 35: 495-516.

Erlandsson M., \& Munro R. (2007) Estimation of the post-mortem interval in beagle dogs. Science Justification 47: 150-154.

Evans D. H., Piermarini P. M. \& Choe K. P. (2005) The multifunctional fish gill: Dominant site of gas exchange, osmoregulation, acid-base regulation, and excretion of nitrogenous waste. Physiology Review 85: 97-177.

Ferguson H. W. (ed.). (2006) Systemic Pathology of Fish, $2^{\text {nd }}$ ed. Scotian Press, London, U.K.

Gatica M. C., Monti G., Gallo C., Knowles T. G. \& Warriss P. D. (2008) Effects of well-boat transportation on the muscle $\mathrm{pH}$ and onset of rigor mortis in Atlantic salmon. Veterinary Record 163: 111-116. 
Heil N. (ed.). (2009) National Wild Fish Health Survey - Laboratory Procedures Manual, $5^{\text {th }}$ Edition. U.S. Fish and Wildlife Service, Warm Springs, GA.

Ilse G., K. Kovacs N. Ryan E. Horvath. \& Ilse D. (1979) Autolytic changes in the rat adenohypophysis: A histologic, immunocytologic and electron microscopic study. Experimental Pathology 17 (4): 185-195.

Jones R. T., \& Trump B.F. (1975) Cellular and subcellular effects of Ischemia on the pancreatic acinar 281 cell: in vitro studies of rat tissue. Virchows Archives B, Cell Pathology Including Molecular Pathology 282 19: 325-336.

Mukundan M. K., Antony P.D., \& Nair, M.R. (1986). A review on autolysis in fish. Fisheries Research 4: $259-269$.

Roberts R. J. (ed.). 2012. Fish Pathology, $4^{\text {th }}$ ed. Blackwell Publishing Ltd., West Sussex, U.K.

Roe W. D., Gartrell B. D., \& Hunter S.A. (2012) Freezing and thawing of pinniped carcasses results in artifacts that resemble traumatic lesions. Veterinary Journal 194: 326-331.

Sterne G. D.,Titley O.G. \& Christie J.L. (2000) A qualitative assessment of various storage conditions on short term preservation of human split skin grafts. British Journal of Plastic Surgery 53: 331-336.

Takeichi S., Tokunaga I., Yoshima K., Maeiwa M., Bando Y., Kominami E., \& Katunuma N. (1984) Mechanism of postmortem autolysis of skeletal muscle. Biochemical Medicine 32: 341-348.

Tavichakorntrakool R., Prasongwattana V., Sriboonlue P., Puapairoj A., Pongskul J., Khuntikeo N., Hanpanich W., Yenchitsomanus P., Wongkham C., Thongboonkerd V. (2008) Serial analyses of postmortem changes in human skeletal muscle: A case study of alterations in proteome profile, histology, electrolyte contents, water composition, and enzyme activity. Proteomics Clinical Application 2: 12551264. 
Thomas P. M., Pankhurst N.W. \& Bremner H.A. (1999) The effect of stress and exercise on post-mortem biochemistry of Atlantic salmon and rainbow trout. Journal of Fisheries Biology 54: 1177-1196.

Tomita Y., Nihira M., Ohno Y., \& Sato S. (1999) Histological study of early postmortem changes in various organs: comparison of the paraffin embedding method and the epoxy resin embedding method. Japanese Journal of Legal Medicine 53(2): 207-217.

Tomita Y., Nihira M., Ohno Y., \& Sato S. (2004) Ultrastructural changes during in situ early postmortem autolysis in kidney, pancreas, liver, heart and skeletal muscle of rats. Legal Medicine 6:2531.

Zdravković M., Kostov M., \& Stojanović M. (2006) Identification of postmortem autolytic changes on the kidney tissue using PAS stained method. Facta Universitatis, Series: Medicine and Biology 13(3): 181-184. 


\section{TABLES}

Table 1: A summary of the experimental design including the following: time of collection, storage method, and temperature of the room and fish. All were performed prior to harvesting each sample.

\begin{tabular}{|c|c|c|c|c|c|}
\hline $\begin{array}{l}\text { Time of } \\
\text { collection }\end{array}$ & \multicolumn{3}{|c|}{ Storage method } & \multirow{2}{*}{$\begin{array}{c}\begin{array}{c}\text { Fish body } \\
\text { temperature }\end{array} \\
\text { Celsius }\end{array}$} & \multirow{2}{*}{$\begin{array}{c}\begin{array}{c}\text { Room } \\
\text { temperature }\end{array} \\
\text { Celsius }\end{array}$} \\
\hline Hours & $\begin{array}{c}\text { Room } \\
\text { temperature }\end{array}$ & Refrigerated & Frozen & & \\
\hline 0 & $\mathrm{X}$ & & & 20.20 & 20 \\
\hline \multirow{3}{*}{4} & $\mathrm{X}$ & & & 18.40 & 20 \\
\hline & & $X$ & & 13.40 & 20 \\
\hline & & & $\mathrm{X}$ & 9.88 & 20 \\
\hline \multirow{3}{*}{24} & $\mathrm{X}$ & & & 18.70 & 20 \\
\hline & & $\mathrm{X}$ & & 3.10 & 20 \\
\hline & & & $\mathrm{X}$ & 1.72 & 20 \\
\hline \multirow{3}{*}{48} & $\mathrm{X}$ & & & 18.20 & 18.89 \\
\hline & & $\mathrm{X}$ & & 3.44 & 18.89 \\
\hline & & & $\mathrm{X}$ & -0.11 & 18.89 \\
\hline
\end{tabular}


285 Table 2: Autolysis Scores ${ }^{\text {a }}$ for Fresh, Refrigerated, Room Temperature, and Frozen Tissue Samples

286 Taken at $0,4,24$, and 48 hours. $^{\text {b }}$

\begin{tabular}{|c|c|c|c|c|c|c|c|c|c|c|}
\hline Samples & Gill arch & Skin & $\begin{array}{l}\text { Skeletal } \\
\text { muscle }\end{array}$ & Kidney & $\begin{array}{l}\text { Liver/ } \\
\text { Pancreas }\end{array}$ & Spleen & Gonads & Heart & GI & Brain \\
\hline $\begin{array}{l}\text { oh } \\
\text { Fresh }\end{array}$ & - & - & - & Minimal & Minimal & - & - & - & - & - \\
\hline 4h Ref. & Minimal & Minimal & Minimal & Minimal & Minimal & Minimal & Minimal & Minimal & Minimal & Minimal \\
\hline $4 \mathrm{~h} \mathrm{Z}$ & Mild & Minimal & $\begin{array}{l}\text { Mild to } \\
\text { moderate }\end{array}$ & Mild & Minimal & Minimal & Minimal & Minimal & Mild & Mild \\
\hline 4h RT & $\begin{array}{l}\text { Mild to } \\
\text { Moderate }\end{array}$ & Minimal & Minimal & Mild & Minimal & Minimal & Minimal & Minimal & Mild & Mild \\
\hline 24h Ref. & Moderate & Minimal & Minimal & Mild & Mild & Mild & Mild & Mild & Mild & Mild \\
\hline $24 \mathrm{~h} \mathrm{Z}$ & Severe & Moderate & $\begin{array}{l}\text { Mild to } \\
\text { moderate }\end{array}$ & $\begin{array}{l}\text { Mild to } \\
\text { moderate }\end{array}$ & $\begin{array}{l}\text { Mild to } \\
\text { moderate }\end{array}$ & $\begin{array}{l}\text { Mild to } \\
\text { moderate }\end{array}$ & Mild & Mild & $\begin{array}{l}\text { Mild to } \\
\text { moderate }\end{array}$ & $\begin{array}{l}\text { Mild to } \\
\text { moderate }\end{array}$ \\
\hline 24h RT & Severe & Moderate & $\begin{array}{l}\text { Mild to } \\
\text { moderate }\end{array}$ & Moderate & Moderate & Moderate & Moderate & Moderate & $\begin{array}{l}\text { Moderate } \\
\text { to severe }\end{array}$ & $\begin{array}{l}\text { Moderate } \\
\text { to severe }\end{array}$ \\
\hline 48h Ref. & $\begin{array}{l}\text { Moderate } \\
\text { to severe }\end{array}$ & Moderate & $\begin{array}{l}\text { Mild to } \\
\text { moderate }\end{array}$ & Moderate & Moderate & $\begin{array}{l}\text { Mild to } \\
\text { moderate }\end{array}$ & $\begin{array}{l}\text { Mild to } \\
\text { moderate }\end{array}$ & $\begin{array}{l}\text { Mild to } \\
\text { moderate }\end{array}$ & Severe & $\begin{array}{l}\text { Mild to } \\
\text { moderate }\end{array}$ \\
\hline 48h RT & Severe & Severe & Moderate & Severe & Severe & Severe & Severe & Severe & Severe & Severe \\
\hline 48h Z & Severe & Severe & $\begin{array}{l}\text { Mild to } \\
\text { moderate }\end{array}$ & Moderate & $\begin{array}{l}\text { Moderate } \\
\text { to severe }\end{array}$ & Moderate & Moderate & $\begin{array}{l}\text { Mild to } \\
\text { moderate }\end{array}$ & $\begin{array}{l}\text { Mild to } \\
\text { Moderate }\end{array}$ & $\begin{array}{l}\text { Mild to } \\
\text { Moderate }\end{array}$ \\
\hline
\end{tabular}

287

288 a Minimal (<5\%); Mild (5-10\%); Moderate (10-50\%); Severe ( $>50 \%)$

289 b Ref., refrigerated; Z, frozen; RT, room temperature; h, hour(s); GI, gastro-intestinal

$290{ }^{c}$ One out of three samples were rare; two out of three were mild 
Figure 1: A, D, G and J. Gill lamellae, formalin-fixed at the time of necropsy (A), after 24 hours at $4^{\circ} \mathrm{C}$ (D), after 48 hours at $4^{\circ} \mathrm{C}(\mathrm{G})$, and thaw $48 \mathrm{~h}$ after being frozen at the time of euthanasia (J).

305

Note the normal filament covered by a closely apposed layer of flat lamellar epithelial cells in the sample formalin fixed at the time of euthanasia (A). After 24 hours (D) or 48 hours (G) at $4^{\circ} \mathrm{C}$, note the widespread epithelial capillary separation, loss of lamellar epithelial cells and dilated extracellular spaces in the filament. These changes are most pronounced in the fish that were frozen at the time of euthanasia and then thawed in water. B, E, H and $\mathrm{K}$. Intestine, formalin-fixed at the time of necropsy (B), after 24 hours at $4^{\circ} \mathrm{C}(\mathrm{E})$, after $48 \mathrm{~h}$ at $4{ }^{\circ} \mathrm{C}(\mathrm{H})$, and thawed $48 \mathrm{~h}$ after being frozen at the time of euthanasia $(\mathrm{K})$. Note the well-preserved epithelial cells in the sample formalin fixed at the time of euthanasia (B) or after 24 hours $(\mathrm{E})$ at $4^{\circ} \mathrm{C}$. After 48 hours $(\mathrm{H})$ at $4^{\circ} \mathrm{C}$, there is marked autolysis with loss of cellular details, epithelial cells and architecture. Mild widespread epithelial separation and loss of cellular details and dilated extracellular spaces were present in the fish that were frozen at the time of euthanasia and then thawed in water (K). C, F, I, L. Liver, formalin-fixed at the time of necropsy (C), after 24 hours at $4^{\circ} \mathrm{C}$ (F), after $48 \mathrm{~h}$ at $4^{\circ} \mathrm{C}$ (I) and thawed $48 \mathrm{~h}$ after being frozen at the time of euthanasia (L). The cellular details and architecture are well-preserved in the samples formalin fixed at the time of euthanasia (C) or mildly decreased in the samples fixed in formalin after 24 hours (F) at $4{ }^{\circ} \mathrm{C}$. After 48 hours (I) at $4^{\circ} \mathrm{C}$, moderate loss of cellular details and widespread cell separation are evident. Loss of cellular details and dilated extracellular spaces were pronounced in the fish that were frozen at the time of euthanasia and then thawed in water (L). Hematoxylin-eosin stain, 400X, bar $=50 \mu \mathrm{m}$. 


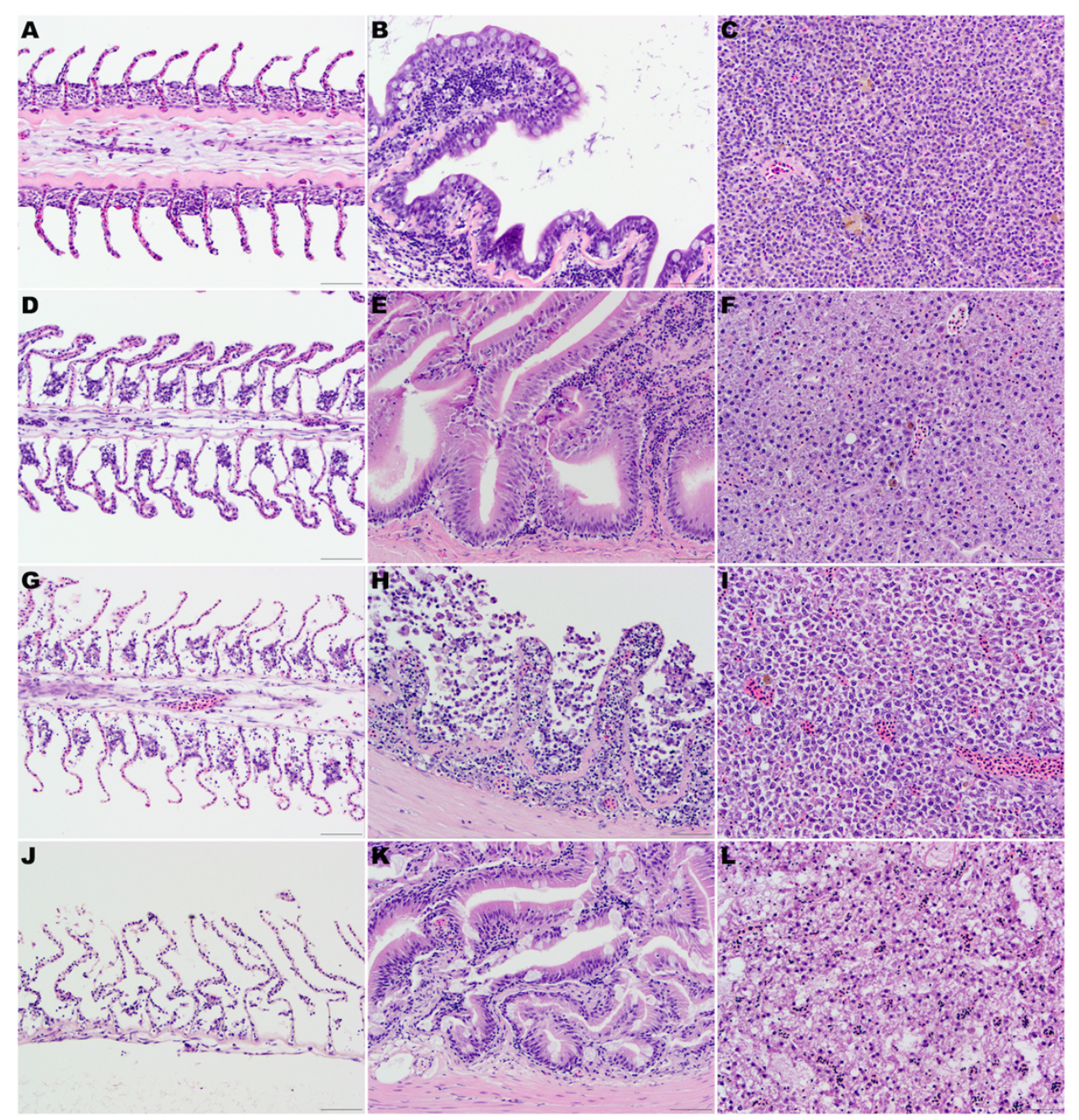


